\title{
O papel das Associações Comunitárias na promoção da confiança do cidadão em instituições públicas
}

De Marchi, Julia; Moraes Pinheiro, Daniel; Pagani, Camila

O papel das Associações Comunitárias na promoção da confiança do cidadão em instituições públicas

Administração Pública e Gestão Social, vol. 13, núm. 3, 2021

Universidade Federal de Viçosa, Brasil

Disponible en: https://www.redalyc. org/articulo.oa?id=351566982006 


\section{O papel das Associações Comunitárias na promoção da confiança do cidadão em instituições públicas}

The role of community associations in promoting citizen trust in public institutions

El papel de las asociaciones comunitarias en la promoción de la confianza ciudadana en las instituciones públicas

Julia De Marchi

Universidade do Estado de Santa Catarina, Brasil

Redalyc: https://www.redalyc.org/articulo.oa?

jd.marchi@yahoo.com.br

Daniel Moraes Pinheiro

Universidade do Estado de Santa Catarina, Brasil

daniel.m.pinheiro@gmail.com

Camila Pagani

Universidade do Estado de Santa Catarina, Brasil

pagani.camila@gmail.com

\section{Resumo:}

Objetivo da pesquisa: Compreender como as associações comunitárias influenciam o desenvolvimento da confiança do cidadão nas instituições públicas.

Enquadramento teórico: A pesquisa tem como referencial teórico as definições de sociedade civil e associações comunitárias, bem como sobre confiança, capital social e cultura política.

Metodologia: Foi utilizada a triangulação de dados como estratégia metodológica. Uma etapa qualitativa deu-se através de entrevistas com gestores públicos, presidentes das associações comunitárias pesquisadas e da observação direta em eventos destas, seguida de análise de conteúdo. Uma etapa quantitativa envolveu a aplicação de questionários junto a moradores do município estudado, seguida por uma análise estatística dos dados.

Resultados: Apesar do reconhecido papel das associações comunitárias junto à realidade local, observa-se baixa participação da população em reuniões e decisões coletivas, levando a ações menos eficazes. Percebeu-se que não há alinhamento na compreensão do papel das associações por parte de cidadãos, gestores públicos e presidentes de associações quanto ao seu papel político. A legitimidade da atuação das associações e a participação nesses espaços influenciam no desenvolvimento da confiança e promoção de cultura política nas instituições públicas, o que não se concretiza integralmente no caso estudado. O baixo nível de participação da comunidade interfere no desempenho das associações e em sua capacidade de gerar capital social.

Originalidade: Estudos sobre associações de moradores, de modo geral, têm como foco o caráter normativo e o papel social destas organizações. Ao considerar seu papel político, aliado ao engajamento cidadão, propõe-se um resgate da importância cívica destas organizações e de seu papel na gestão da vida política nas cidades.

Contribuições teóricas e práticas: Os resultados evidenciam a importância das associações comunitárias como promotoras de cultura política e capital social e permitem repensar aspectos práticos da gestão dessas organizações e suas contribuições para perspectivas comunitárias da administração pública e da gestão social.

PalaVRas-CHAVE: participação social, engajamento, cultura política, capital social.

\section{Abstract:}

Research objective: The objective of this study is to understand how community associations influence the development of citizen confidence in public institutions.

Theoretical framework: The research has as a theoretical framework the definitions of civil society and community associations, as well as on trust, social capital and political culture.

Methodology: Data triangulation was used as a methodological strategy. A qualitative step took place through interviews with public managers, presidents of the researched community associations and direct observation at events of the associations, followed 
by content analysis. A quantitative step involved the application of questionnaires to the residents of the municipality studied, followed by a statistical analysis of the data.

Results: Despite the recognized role of community associations in the local reality, there is a low participation of the population in meetings and collective decisions, leading to less effective actions. It was noticed that there is no alignment in the understanding of the role of associations by citizens, public managers and presidents of associations regarding their political role. The legitimacy of the associations' activities and participation in these spaces influence the development of trust and the promotion of political culture in public institutions, which is not fully realized in the case studied. The low level of community participation interferes with the performance of associations and their ability to generate social capital.

Originality: Studies on residents' associations, in general, focus on the normative character and social role of these organizations. When considering their political role, coupled with citizen engagement, they propose to rescue the civic importance of these organizations and their role in the management of political life in cities.

Theoretical and practical contributions: The results show the importance of community associations as promoters of political culture and social capital and allow rethinking practical aspects of the management of these organizations and their contributions to community perspectives of public administration and social management.

KEYWORDS: social participation, engagement, political culture, social capital.

\section{ReSUMEN:}

Objetivo de la investigación: Comprender cómo las asociaciones comunitarias influyen en el desarrollo de la confianza ciudadana en las instituciones públicas.

Marco teórico: La investigación tiene como marco teórico las definiciones de sociedad civil y asociaciones comunitarias, así como sobre confianza, capital social y cultura política.

Metodología: Se utilizó la triangulación de datos como estrategia metodológica. Se dio un paso cualitativo a través de entrevistas con los administradores públicos, presidentes de las asociaciones comunitarias investigadas y la observación directa de los eventos de las asociaciones, seguida de un análisis de contenido. Un paso cuantitativo implicó la aplicación de cuestionarios a los residentes del municipio estudiado, seguido de un análisis estadístico de los datos.

Resultados: A pesar del reconocido rol de las asociaciones comunitarias en la realidad local, existe una baja participación de la población en reuniones y decisiones colectivas, lo que lleva a acciones menos efectivas. Se observó que no existe alineación en la comprensión del rol de las asociaciones por parte de los ciudadanos, los administradores públicos y los presidentes de asociaciones en cuanto a su rol político. La legitimidad de las actividades de las asociaciones y la participación en estos espacios influyen en el desarrollo de la confianza y la promoción de la cultura política en las instituciones públicas, lo que no se concreta plenamente en el caso estudiado. El bajo nivel de participación comunitaria interfiere en el desempeño de las asociaciones y su capacidad para generar capital social.

Originalidad: Los estudios sobre las asociaciones de vecinos, en general, se centran en el carácter normativo y el papel social de estas organizaciones. Al considerar su rol político, sumado al compromiso ciudadano, proponen rescatar la importancia cívica de estas organizaciones y su rol en la gestión de la vida política en las ciudades.

Aportes teóricos y prácticos: Los resultados muestran la importancia de las asociaciones comunitarias como impulsoras de la cultura política y el capital social y permiten repensar aspectos prácticos de la gestión de estas organizaciones y sus aportes a las perspectivas comunitarias de la administración pública y la gestión social.

Palabras Clave: Participación social, Compromiso, Cultura política, Capital social.

\section{INTRODUÇÃO}

As associações comunitárias, enquanto organizações da sociedade civil, são importantes catalisadoras do capital social, bem como lastros para o entendimento da confiança dos cidadãos nas instituições. Essas organizações possuem estruturas que, em tese, as permitem lutar pelos interesses da comunidade junto ao poder público, para que a localidade usufrua dos seus direitos. Para tanto, a participação é um dos princípios fundamentais no processo de fortalecimento de uma associação. É a partir dela que acontece o envolvimento dos cidadãos na tomada de decisão e na busca de soluções para as necessidades comuns, reforçando o sentido de comunidade e fortalecendo os laços sociais e o desenvolvimento local.

As associações comunitárias representam uma maneira de unir as pessoas em prol do bem comum e do compromisso coletivo, na medida em que atuam mais diretamente em uma realidade local. Como entes da 
sociedade civil, podem servir como um meio para ampliar discursos e, portanto, gerar efeitos na esfera pública, facilitar a comunicação e a inclusão (Habermas, 1996).

As associações comunitárias constituem, assim, expressões da ação democrática e de sua essência. Ao sugerir distintas abordagens teóricas da democracia, Lüchmann (2016) apresenta diversos benefícios da atuação das associações como elementos ativos do processo democrático e de seu fortalecimento. Na democracia participativa, resgata-se a ideia de autogoverno e soberania popular por meio da participação nos processos de discussão e decisão política. Na democracia associativa, enfatiza-se o papel das associações nos processos de ampliação da democracia a partir da constatação dos limites das instituições públicas tradicionais, como Estado e partidos políticos, ante o aumento da complexidade dos fenômenos sociais. Já na democracia deliberativa, orientada pelos princípios de inclusão, pluralismo, igualdade participativa e bem comum, enquadra-se as associações na definição de sociedade civil, ator central na esfera pública com capacidade de influir nos mecanismos tradicionais de formulação de regras e políticas (Lüchmann, 2016).

Para Fung (2003), as associações podem contribuir para socialização cívica e para educação política, na medida em que afetam atitudes e comportamentos dos indivíduos indicando virtudes cívicas como atenção ao bem público, cooperação, tolerância, respeito ao próximo e ao estado de direito. Por meio da educação política, as associações inserem o cidadão em sua realidade e o torna capaz de participar, cobrar, intervir e reivindicar. Ademais, podem promover melhorias nas maneiras pelas quais os interesses são representados junto aos legisladores e traduzidos em leis, oferecendo canais para que os cidadãos possam expor e cobrar suas demandas públicas (Fung, 2003).

A conveniência de várias contribuições associativas para a democracia depende das características de contextos políticos particulares (Fung, 2003), afinal, alguns limites desafiam sua efetividade, como a relação clientelista e paternalista que permeia todas as esferas sociopolíticas do país. Para Gomes (2015), tal relação envolve o provimento de proteção e assistência de forma direta por uma determinada pessoa (patrão) para pessoas (clientes) que dependem dele. Esta relação clientelista vai de encontro ao exercício da cidadania na medida em que é regulada em função de uma hierarquia de prestígio e poder (Gomes, 2015), inibindo a ação coletiva organizada. Esta prática distorce o significado de participação política e limita a formação de grupos de interesse organizados de forma autônoma.

As práticas clientelistas reforçam o paternalismo impregnado nas comunidades e presente na cultura política brasileira. Segundo O’Donnell (1987), a democracia pressupõe distinção entre o que é público e o que é privado para orientar a prática dos governantes e a cobrança pela população. A configuração do Estado brasileiro, entretanto, demonstra que "a falta desta distinção [entre público e privado] leva ao arbítrio, à corrupção, ao paternalismo, ao empreguismo e ao clientelismo" (Gomes, 2015, p. 12). Esta configuração resulta em uma política através da qual a população mais carente só tem acesso a algum tipo de proteção social, geralmente, pelo viés do favorecimento.

Além das práticas clientelistas, Ansell (2012) argumenta que é necessário dar um passo contraintuitivo para aqueles que consideram a burocracia como a causa de desconfianças no aparato estatal. É preciso ver os órgãos públicos como uma parte essencial da solução. Enquanto imperativo de interação, a confiança está na essência das relações causais complexas que vinculam as crenças e ações de indivíduos ao funcionamento de organizações e instituições, levando a resultados positivos coletivos e individuais.

No entanto, a falta de compromisso da comunidade também é um desafio. O não entendimento por parte do cidadão sobre a importância da participação nas atividades de organizações como as associações comunitárias, não assumindo seu papel e não reconhecendo o papel da instituição na sociedade, fazem com que as pessoas se distanciem deste espaço, interessando-se e participando cada vez menos.

O cenário de corrupção no Brasil levou à desconfiança por parte da população e a um envolvimento político inversamente proporcional. Do ponto de vista da atuação política, o enfraquecimento das associações comunitárias nas últimas décadas e a visão de que estas não seriam espaços políticos, quando na verdade esse deveria ser o seu real papel, gera não apenas uma baixa representatividade, mas também deslegitima sua ação. 
Historicamente, muitas associações passaram a ser utilizadas como "trampolim eleitoral", deixando-se de lado a busca pela participação e melhoria da comunidade para utilizá-las como espaços de interesse pessoal e político-partidário. Diante disso, por mais que as associações possuam um papel central no desenvolvimento comunitário, é possível perceber que ainda há um longo caminho a ser percorrido, começando pelo resgate do senso de participação e dever cívico e o fortalecimento dos espaços de exercício da cidadania.

Além da privatização do Estado marcada por práticas de favorecimento, a falta de transparência dos atos públicos e a dificuldade de acesso a esses órgãos também pode desestimular a participação e o engajamento. Dessa forma, é necessário compreender a relação entre as instituições e a comunidade para a promoção de práticas de diálogo e cooperação. As associações comunitárias surgem no sentido de promover novos espaços de diálogo, com o respaldo da comunidade, a partir de uma proposta de participação efetiva e de cobrança constante, especialmente frente ao poder público, buscando o atendimento de demandas sociais por meios constitucionais e democráticos.

Nesse sentido, este artigo tem como objetivo compreender como as associaçóes têm desempenhado o seu papel no desenvolvimento da confiança dos cidadãos nas instituições públicas, a partir da visão dos atores envolvidos. Para tanto, o estudo realizado no município de São José (SC) envolveu o contato com as associações comunitárias ativas no município. Os resultados da pesquisa evidenciam a importância das associações comunitárias como promotoras de cultura política e capital social, considerando os valores intrínsecos de confiança e participação como fundamentais à atividade política e ao processo democrático. Ao mesmo tempo, expõe limites do contexto político particular (Fung, 2003) atinentes às relações entre Estado e sociedade civil e advindos da própria cultura de desconfiança nas instituições públicas.

A pesquisa se dá a partir do levantamento da percepção da comunidade, de gestores do poder público municipal e dos presidentes das associações. Cabe considerar o contexto de crise econômica e política vivida nos últimos anos, bem como a sistemática perda de confiança nas instituições públicas e nas ações políticas. Desta forma, o estudo aborda a confluência de conceitos como capital social, cultura política e confiança, e o papel das associações comunitárias em relação a estes.

\section{SOCIEDADE CIVIL E ASSOCIAÇÕes COMUNITÁRIAS NO BRASIL}

O conceito de sociedade civil surgiu como contraposição das esferas pública e privada, sendo descrita muitas vezes como "esfera das relações sociais não reguladas pelo Estado" (Bobbio, 2007, p. 33). Todavia, esta contraposição não significa o isolamento do setor, pois sua existência está ligada ao constante relacionamento com ambas as esferas. Heideman (2018) reafirma que, enquanto é difícil definir sociedade civil, esta é entendida de modo geral como um espaço intermediário entre Estado e sociedade, constituído por cidadãos que trabalham em conjunto em busca de objetivos comuns.

A noção de sociedade civil na atualidade pressupõe uma retomada de discussão sobre questões políticas pelos atores sociais, de tal forma que a resolução de problemas sociais e a busca pela garantia de direitos sejam enfrentados de maneira coletiva (Andion \& Serva, 2004). Assim, tem-se uma visão "positiva” do conceito de sociedade civil (Andion \& Serva, 2004; Cohen \& Arato, 1994) a partir da interface com outras esferas sociais, economia e Estado. Segundo Habermas (1996),

A sociedade civil é composta por aquelas associações mais ou menos espontaneamente aderentes, organizações e movimentos que, sintonizados com a forma como os problemas sociais ressoam nas esferas da vida privada, destilam e transmitem tais reações de forma ampliada para a esfera pública. $\mathrm{O}$ núcleo da sociedade civil compreende uma rede de associações que institucionaliza discursos de resolução de problemas sobre questóes de interesse geral dentro do quadro de esferas públicas organizadas. Esses "modelos discursivos" têm uma forma igualitária e aberta de organização que espelha características essenciais do tipo de comunicação em torno do qual eles se cristalizam e ao qual dão continuidade e permanência. (p. 367 , tradução nossa) 
A sociedade civil também pode ser definida como uma esfera particular de interação social, com um papel específico, diferente das esferas econômica e estatal (Andion \& Serva, 2004; Avritzer, 2012; Cohen, 2007). A comunicação entre as esferas se daria por exemplo através das associações voluntárias e comunitárias, dos movimentos sociais, dos veículos de comunicação pública e outras instituições de fronteira que possibilitem esta conexão. Habermas (1996, p.367, tradução nossa) completa que a sociedade civil é constituída "por cidadãos que procuram interpretações aceitáveis para seus interesses e experiências sociais e que desejam ter uma influência na formação institucionalizada de opiniões e vontades".

Cohen (2007) acrescenta que a sociedade civil é caracterizada pela pluralidade, privacidade e publicidade. Trata-se, pois, de um campo complexo, plural, composto por múltiplas formas organizativas, desde as filantrópicas até grupos críticos mais radicais, sendo os movimentos sociais seus principais representantes (Dagnino, 1998). A privacidade, segundo Cohen (2007), refere-se à autonomia em relação ao Estado e ao mercado, na medida em que os objetivos de associação não coincidem diretamente com os objetivos de tomada de decisão e poder político, nem com a busca de lucros (Cohen, 2007; Dagnino, 1998). No entanto, Lavalle e Szwako (2015) argumentam que sociedade civil e Estado são mutuamente constitutivos e a invocação da "autonomia" não implica ausência de interação. Ainda, a publicidade, no sentido de dar "voz" aos indivíduos que podem apresentar suas demandas, promove oportunidade de reivindicação por mais liberdade e justiça social (Andion \& Serva, 2004; Cohen, 2007; Dagnino, 1998).

Sob este viés, as associações de moradores buscaram renovar a prática da cidadania nos bairros e fortalecer a participação social. Porém, antes do surgimento das associações de bairro, outros movimentos foram organizados, como é o caso das Sociedades Amigos de Bairro, que apareceram nas décadas de 1950 e 60. Segundo Abers (1998, p. 52), "essas primeiras associações de bairro, formadas em grande parte por moradores pobres em busca da extensão de serviços públicos a seus bairros, raramente mobilizavam grande número de pessoas". Ainda, elas se atrelaram a interesses políticos que não necessariamente respondiam pelos interesses coletivos, configurando-se essencialmente como paternalistas e clientelistas.

Com o fim da ditadura militar, a sociedade civil encontra-se num processo de institucionalização (Andion \& Serva, 2004) com a criação de diversas entidades. A Constituição de 1988 promoveu melhorias no âmbito social quanto ao aumento dos direitos de cidadania e descentralização das políticas sociais, fortalecendo o exercício da democracia. O período de redemocratização permitiu que o debate sobre o papel das organizações sociais e sua consolidação no campo institucional fosse efetivo, a exemplo do estabelecimento da OSCIP (Organização da Sociedade Civil de Interesse Público), a partir da realização de fóruns locais com vistas ao fortalecimento das entidades representativas, possibilitando a criação de projetos e programas sociais através de parcerias formais entre as diversas esferas da sociedade.

Lüchmann (2016) acrescenta que este processo de institucionalização diz respeito aos mecanismos de organização formais necessários e à participação crescente da sociedade civil nos espaços de gestão de políticas públicas como os Conselhos Gestores implementados em diferentes áreas no país. Durante esse período, alguns grupos começaram a contestar o caráter clientelista predominante nas associações, levando ao surgimento de organizações mais abertas e participativas (Abers, 1998). Houve um crescimento do associativismo, inibido até então pelo regime autoritário, e uma mudança no perfil associativo que até então era apolítico, assistencialista, religioso ou de lazer, mudando para um associativismo de cunho político, propositivo e contestatório (Lüchmann, 2016).

Diante de um cenário de mais de vinte anos de centralização do Estado, de uma cidadania regulada e de uma ditadura militar, o termo sociedade civil é aplicado ao que emerge da sociedade sem o controle do Estado (Dagnino, 1998). O cenário atual traz perspectivas e desafios para a sociedade civil, especialmente no que concerne a persistência da autonomia dentro da visão positiva do conceito, ou seja, uma sociedade civil propositiva que mantém interface com o Estado e com o mercado em formato de parcerias, conservando a visão no bem comum. 


\section{AsSOCIAÇões COMUNiTÁRIAS SOB A PERSPECTIVA DA CONFIANÇA, DA CULTURA POLÍTICA E DO CAPITAL SOCIAL}

Associações comunitárias são organizações formais, criadas a partir da união de ideias e objetivos comuns. Elas têm como papel a centralização da força dos moradores da comunidade e buscam representar, de maneira mais eficaz, as necessidades e anseios da localidade em que estão inseridas. Originam-se da participação espontânea dos moradores locais, onde cada bairro tem cultura, costumes e práticas próprias que influenciam na tomada de decisão. Logo, a associação é formada por diferentes visões e concepções da realidade. Segundo Araujo, Tolentino e Theophilo (2009, p. 06), "a proximidade geográfica é um dos aspectos fundamentais, que fortalecem a convivência social e cultural, estabelecendo assim, um modo particular de se viver".

Lüchmann (2016) sugere que as associações comunitárias estão mais próximas da ideia de ajuda mútua e que os membros destas organizações são ao mesmo tempo agentes e beneficiários do trabalho desenvolvido por elas. A importância dessas associações para o desenvolvimento local se dá na medida em que podem provocar as autoridades na tomada de atitudes concretas em prol da comunidade e da melhoria de qualidade de vida dos bairros, portanto, o processo de fortalecimento de uma associação tem como um de seus princípios a participação da comunidade como um todo, pois é através dela que acontece o engajamento dos cidadãos na tomada de decisão e busca de soluções para as necessidades comuns, fortalecendo os laços sociais. Abers (1998, p. 50) ressalta que "onde a cooperação não é comum, as pessoas se ressentem da falta de bases para confiança mútua”, por isso, antes de tudo é necessário que haja um entendimento das potencialidades do processo de participação e cooperação. Abers (1998) indica ainda que "as pessoas se mobilizam quando percebem 'janelas de oportunidade' que os convençam de que a ação provavelmente dará resultados. Frequentemente, tais 'contextos favoráveis' estão associados a mudanças na estrutura de poder do Estado” (Abers, 1998, p. 69).

A associação é um dos principais acessos aos acontecimentos políticos e econômicos da região, o que favorece o engajamento da comunidade no debate político, levando a um aperfeiçoamento da democracia (Araujo, Tolentino \& Theophilo, 2009). Neste caso, o fator essencial é a participação, a qual é determinada pela confiança social, pela cultura política e por seus elementos fundamentais no fortalecimento de valores democráticos (Baquero, 2008; Inkeles, 2001). Para Jacobi (1980, p. 233), a mobilização da comunidade indica um "avanço nos níveis de consciência e de organização da população na construção de uma real prática democrática”, contudo, a construção histórica do Brasil, com heranças patrimonialistas e clientelistas, tornou o Estado menos aberto à participação popular, concentrando em si o poder de decisão. Baquero (2008) acrescenta que estas características históricas levaram a uma desconfiança, por parte da população, no aparato governamental e nas regras do contrato social, e, considerando que após algumas décadas o panorama continua o mesmo, Baquero (2008) ressalta que,

O quadro atual da democracia brasileira sinaliza as dificuldades que o governo enfrenta na aplicação de políticas públicas em um ambiente de desconfiança que significa distanciamento, indiferença, falta de reciprocidade e de solidariedade social. Um ambiente com essas características dificilmente conduz ao fortalecimento e muito menos à consolidação de uma cultura política democrática (entendida na sua dimensão social). (p. 396)

Baquero (2008) lembra que o componente essencial da democracia é o capital social. Entendido como uma forma de facilitar a cooperação mútua (Putnam, 2005), o capital social refere-se aos "traços da rede da vida social, normas e confiança, que habilitam os participantes a agirem em conjunto, mais efetivamente, para buscarem os objetivos compartilhados" (Teixeira \& Popadiuk, 2003, p. 75)

A confiança é entendida como um dos elementos-chave do capital social, responsável por facilitar a cooperação entre os indivíduos de uma comunidade que, juntos, ganham poder para interferir nos processos políticos, resolvendo problemas comuns e facilitando o controle social. Nesse sentido, a cooperação é diretamente proporcional ao nível de confiança numa comunidade, gerando um ciclo que se retroalimenta. 
Baquero (2003, p. 94) acrescenta que o capital social pode ser entendido, sob uma perspectiva ideológica, como "empowerment da cidadania, o pluralismo e a democratização", contudo, as definições abordadas pela maioria dos autores (Baquero, 2003, 2008; Fukuyama, 1995; Putnam, 2005; Teixeira \& Popadiuk, 2003) são aquelas que vinculam o capital social à confiança nas relações sociais.

A capacidade de socialização do indivíduo é elemento essencial para o entendimento do que é capital social e do significado de cultura política. Segundo Kuschnir e Carneiro (1999, p. 227), "a noção de cultura política refere-se ao conjunto de atitudes, crenças e sentimentos que dão ordem e significado a um processo político, pondo em evidência as regras e pressupostos nos quais se baseia o comportamento de seus atores". No âmbito subjetivo de um determinado sistema político, é vista ao mesmo tempo como causa e consequência do funcionamento deste.

Laniado (2001, p. 228) sugere que a reciprocidade e a confiança são fatores essenciais ao entendimento dos princípios de cultura política nas sociedades modernas. Dessa forma, o conceito de cultura política não pode ser separado da ideia do modelo de democracia participativa. Alguns autores (Baquero, 2001; Kuschnir \& Carneiro, 1999; Laniado, 2001) caracterizam cultura política democrática por aspectos como a socialização, adesão às normas, transmissão de valores e a participação.

Baquero (2001) sugere que a cultura política não diz respeito apenas à transmissão de valores políticos, mas também legitima o funcionamento das instituições políticas. Apesar dessa evidência, o autor lembra que se está longe de construir uma cultura política democrática e participativa, ainda fragmentada e individualista. Ou seja, o capital social não é suficiente e o cenário de desconfiança interpessoal e nas instituições ainda prevalece.

Ademais, há a necessidade de entender a capacidade de adesão dos indivíduos aos valores e normas atrelados a uma sociedade democrática (Laniado, 2011). Kuschnir e Carneiro (1999) enfatizam que em um processo democrático, se o impacto é gerado apenas no sistema político-institucional e não é acompanhado por mudanças nos processos de socialização, o regime se torna instável e tende a perder legitimidade.

Para Baquero (2008), as Associações Comunitárias são consideradas catalisadoras do capital social, principalmente no que se refere às camadas mais pobres. "Essas redes podem ser ativadas para facilitar a ação coletiva que seja benéfica não somente para os indivíduos, mas, sobretudo, para as comunidades" (Baquero, 2008, p. 397). Essa atuação em rede traz novamente à tona a importância da confiança. Vale destacar também que "a associabilidade consiste na disposição de subordinar os objetivos individuais aos objetivos da organização e a confiança é pré-requisito e resultado do sucesso da ação coletiva” (Teixeira \& Popadiuk, 2003, p. 76).

O grau de envolvimento dos cidadãos na política, seja por mecanismos formais ou informais, é um elemento fundamental para se determinar a qualidade de uma democracia (Baquero, 2008). O autor ressalta ainda que "há um consenso de que sem o envolvimento popular no processo de construção democrática ela perde em legitimidade, mantendo simplesmente sua dimensão formal” (Baquero, 2008, p. 381). Neste sentido, tomando como exemplo os partidos políticos, percebe-se que os eleitores muitas vezes não se identificam com esta forma de organização, já que possuem características de representação de interesses particularizados. Diante disso, muitos cidadãos buscam outros mecanismos de defesa de seus interesses e, quando interessa participar, buscam outras formas de organização, como é o caso das associações comunitárias.

A participação em associações produz capital social significativo, ou seja, promove o engajamento político (Baquero, 2003). A participação na definição de agendas de políticas públicas, ou mesmo de cobrança por direitos fundamentais, não fica restrito a uma única pessoa, mas a um grupo de pessoas ou uma comunidade, que tem nas associações um meio de buscar alternativas. Como visto, os atores que compõem as associações são ao mesmo tempo agentes de trabalho e beneficiários daquilo que elas buscam. Cabe, entretanto, entender que apesar da autonomia destas formas organizativas, elas não conseguem se sustentar sem a interface com o Estado e com o mercado em forma de parcerias. 
Diante do exposto, o arcabouço teórico apresentado permite que os elementos essenciais, como participação, política e democracia, passem a definir as dimensões de análise, juntamente com o papel das associações. Portanto, as etapas da pesquisa foram construídas no sentido de cumprir com o objetivo central do trabalho.

\section{Metodologia}

Trata-se de uma pesquisa quali-quantitativa de caráter descritivo. O estudo foi dividido em duas etapas, sendo a primeira essencialmente qualitativa, utilizando-se da análise documental, observação direta e aplicação de entrevistas semiestruturadas. $\mathrm{Na}$ etapa de análise documental buscou-se o registro de fundação e atas de reuniões das associações ativas no município, as quais não foram encontradas nos registros de Prefeitura Municipal, nem fornecidas pelos responsáveis pelas associações. Por meio da observação e das entrevistas, buscou-se analisar as perspectivas dos gestores das associações, de representantes do poder público municipal e de moradores da comunidade em relação ao tema e obter informações históricas essenciais para o entendimento da problemática.

Foram entrevistados dois gestores do poder público executivo municipal e três presidentes de diferentes associações ativas, além do acompanhamento de algumas ações das associações. A escolha desses entrevistados se deve à busca por uma visão plural do fenômeno, tendo em vista que as associações comunitárias devem servir como ponte entre a população e as organizações públicas, principalmente as prefeituras. Portanto, entender a visão dos gestores públicos municipais é fundamental, uma vez que a percepção destes sobre as associações influencia na sua abertura à comunicação com a sociedade.

A escolha do município de São José se deu devido à sua representatividade como quarto maior município do Estado de Santa Catarina em termos populacionais e à sua proximidade com os pesquisadores, sendo critério determinante, facilitando, assim, a busca e o contato com os entrevistados. A aproximação ocorreu através das redes de contato informais estabelecidas dentro da Prefeitura, que possibilitou um levantamento das Associações de Moradores ativas nos bairros, seus respectivos representantes e contatos. Após, foi realizada uma tentativa de agendamento com cada um deles, na sede da associação ou durante algum evento desta. A escolha dos gestores municipais se deu quanto à proximidade destes em relação às demandas locais e sua experiência prévia com representantes de alguma associação.

Nesta etapa foram desenvolvidas algumas questões que orientaram a coleta de dados primária e secundária: (a) Qual o papel desempenhado pelas associações comunitárias?; (b) Os gestores, as instituições públicas e a comunidade têm pleno conhecimento de tal papel?; (c) Como esses atores percebem as associações comunitárias?; (d) Essas associações comunitárias estão desempenhando seu papel efetivamente? Se sim, através de que mecanismos? Se não, por quê?

Foram estabelecidos ainda alguns pressupostos $(\mathrm{Pn})$ com base na realidade encontrada e no referencial teórico: (P1) As associações comunitárias exercem importante papel no desenvolvimento da confiança das pessoas nas instituições públicas; (P2) Os gestores das associações comunitárias do município possuem pleno conhecimento do papel desempenhado por elas; (P3) As instituições públicas locais estão abertas à participação e reconhecem o papel das associações; (P4) A comunidade reconhece o papel das associações e participa ativamente; (P5) Os gestores percebem essas associações como um meio de participação e de luta por melhorias na comunidade, bem como fundamentais para o desenvolvimento do capital social e da confiança nas instituições públicas; (P6) A confiança dos cidadãos nas instituições públicas aumenta quando as associações comunitárias desempenham seu papel efetivamente.

Devido à necessidade de coleta de um volume maior de dados, realizou-se uma segunda etapa, quantitativa, com a aplicação de um questionário a moradores do município. Objetivou-se, assim, compreender qual a visão da comunidade sobre a importância das associações de bairro, além de questões como o papel desempenhado por elas, sua influência e abertura à participação. 
Para a fase quantitativa, a amostra foi não probabilística. Considerando o número de habitantes de São José, uma margem de erro de 6\%, e um nível de confiança de 95\%, estimou-se uma amostra de 280 respondentes. Obteve-se um total de 284 respostas válidas. As entrevistas e o questionário foram realizados durante o segundo semestre de 2017.

A análise dos dados coletados, tanto pela observação e entrevistas, quanto pela aplicação do questionário, foi feita com base nas dimensões de análise estabelecidas a partir do método de análise de conteúdo, na etapa qualitativa, e do uso de estatística descritiva simples, na etapa quantitativa.

\section{CaracterizaÇÃo e descrição do Campo: Associações de Moradores de SÃo José}

São José é o quarto maior município do estado de Santa Catarina em número de habitantes, e faz parte da região metropolitana de Florianópolis, capital do estado. Segundo dados do Instituto Brasileiro de Geografia e Estatística (IBGE) de 2018, a cidade possui uma população estimada de 242.927 habitantes e uma área territorial de $150.453 \mathrm{~km}^{2}$, que é composta por 28 bairros, divido em 3 distritos.

O município conta com diversas Associações de Moradores (AM), no entanto, não há um cadastro geral onde se possa encontrá-las. Em pesquisa realizada foi possível verificar o registro formal de pelo menos cinco associações, entretanto, estima-se que muitas mais funcionem de maneira informal dentro dos bairros. Entre as instituições em funcionamento durante a pesquisa, estão:

- AM do bairro Ponta de Baixo, localizada no bairro Ponta de Baixo;

- AM do Parque Residencial do Lisboa, localizada no bairro Forquilhas;

- AM do Parque Residencial Ceniro Martins, localizada no bairro Forquilhas;

- AM da Serraria, localizada no bairro Serraria;

- AM do Jardim Los Angeles, localizada no bairro Forquilhas.

Algumas dificuldades foram encontradas durante a fase de coleta de dados. Inicialmente não foi possível acessar documentos ou dados na Prefeitura Municipal de São José e, em contato com alguns presidentes, houve resistência na entrega desses documentos. Boa parte das AM não realizava reuniões periódicas ou possuía um representante eleito, limitando o número de associações passíveis de investigação e dificultando a observação, entretanto, foi possível realizar a observação de ações comunitárias em um dos bairros, bem como de ações do executivo e legislativo municipal. Apesar das dificuldades encontradas, foi possível conhecer a visão dos presidentes sobre o papel das associações e questões como confiança e cultura política.

\section{Dimensões DE ANÁLISE}

As entrevistas realizadas e a análise dos dados coletados basearam-se em quatro dimensões: participação, percepção do papel das associações, dimensão política e capital social e democracia. Foram identificados os principais papeis das associações, apontados pelos entrevistados e respondentes, bem como alguns problemas atinentes a atuação dos gestores e perspectiva dos atores envolvidos, os quais serão apresentados na análise final.

As dimensões de análise foram definidas a partir da revisão de literatura sobre sociedade civil, mais especificamente sobre associações comunitárias, e alinhadas aos objetivos e pressupostos desta pesquisa. São considerados, portanto, elementos balizadores para a análise. Cada uma das dimensões, como apresentadas no Quadro 1, traz elementos - aqui caracterizados em relação ao papel da associação - que auxiliaram no processo de análise dos dados. 
Quadro 2 - Associações de moradores e problemáticas encontradas

\begin{tabular}{|c|c|}
\hline Dimensão & Papel da Associação \\
\hline Participação & $\begin{array}{l}\text { União da Comunidade; } \\
\text { Coprodução do Bem } \\
\text { Público; Representatividade } \\
\text { local junto ao Estado; }\end{array}$ \\
\hline $\begin{array}{l}\text { Percepção } \\
\text { do Papel } \\
\text { das } \\
\text { Associações }\end{array}$ & $\begin{array}{l}\text { Buscar melhorias para o } \\
\text { bairro; Exercer a } \\
\text { representação política dos } \\
\text { moradores; Promover a } \\
\text { formação de agenda junto } \\
\text { ao poder público; Canal de } \\
\text { comunicação com as } \\
\text { instituições públicas; } \\
\text { Aproximar o cidadão do } \\
\text { poder público e das } \\
\text { políticas públicas; Provocar } \\
\text { as autoridades na tomada } \\
\text { de decisão; Exercer o } \\
\text { controle social; Permitir } \\
\text { acesso aos acontecimentos } \\
\text { políticos e econômicos da } \\
\text { regiấo; }\end{array}$ \\
\hline Política & $\begin{array}{l}\text { Atuar como canal de } \\
\text { comunicação e promoção } \\
\text { do debate; Promover a } \\
\text { educação política, a } \\
\text { conscientização e a } \\
\text { politização dos cidadãos; } \\
\text { Ampliar a capacidade de } \\
\text { representação política; }\end{array}$ \\
\hline Democracia & $\begin{array}{l}\text { Aproximar-se da } \\
\text { populaçăo; Fortalecer a } \\
\text { confiança do cidadão nas } \\
\text { instituiçôes públicas; } \\
\text { Contribuir para o } \\
\text { fortalecimento da } \\
\text { democracia, através da } \\
\text { construção de interesses } \\
\text { comuns; Promover o } \\
\text { engajamento da população } \\
\text { nos debates políticos; } \\
\text { Promover a união dos } \\
\text { moradores e o } \\
\text { desenvolvimento de capital } \\
\text { social; }\end{array}$ \\
\hline
\end{tabular}

\section{Dimensão 1: Participação}

A ideia de que o "ato de governar" era de responsabilidade predominantemente do Estado perdurou por muito tempo e só recentemente as análises apontaram para uma transformação nessa percepção, enfatizando a influência de diferentes atores e redes que estabelecem relações de cooperação e também de concorrência (Andion, Ronconi, Moraes, Gonsalves \& Serafim, 2017). Essa ideia é corroborada pelo entrevistado P1 (Presidente 1), que acredita que o papel da associação tem como essência a adesão da comunidade e a coprodução em busca de melhorias para o seu bairro. Segundo este entrevistado, o erro das outras associações é de não trabalhar em conjunto com a esfera pública, tornando-a unicamente responsável pela implementação de políticas públicas. Esta perspectiva vai ao encontro do que apontam Lavalle e Szwako (2015), de que a sociedade civil e Estado são mutuamente constitutivos e pressupõem interação. 
A participação é, portanto, fator essencial para a efetividade da associação, porém, $90 \%$ dos respondentes declararam não participar ativamente da associação de moradores do seu bairro. Neste mesmo sentido, mais de $80 \%$ afirmaram nunca terem participado de reuniões ou ações da associação, o que confirma não apenas a falta de participação, mas também a dificuldade de ação e legitimidade das associações. Os dados vão ao encontro do relato do entrevistado P1, segundo o qual a participação melhorou ao longo dos anos, porém ainda está aquém do ideal: "As pessoas não participavam, então, com tudo que foi desenvolvido na comunidade, com o trabalho feito, algumas pessoas começaram a despertar . . só que a maioria não quer participar ativamente, não quer assumir um compromisso". O presidente acredita que esta baixa participação se deve à falta de espírito coletivo por parte da população. Com relação a isto, foi possível observar durante uma das ações da associação, a limpeza da praça principal do bairro aos sábados de manhã, da qual apenas três moradores participaram, sendo que destes, dois faziam parte da gestão da associação. Eles apontaram que alguns dos vizinhos, apesar de morarem em frente à praça, não auxiliam na limpeza desta e ainda seriam responsáveis por parte do lixo deixado ali.

Em contrapartida, o P2 (Presidente 2) acredita que a baixa participação em seu bairro se deve à alta rotatividade de moradores, o que leva a não identificação com as causas do bairro. Isso é facilmente percebido quando analisadas as respostas quanto ao conhecimento da existência de uma associação de moradores no bairro. Quase 70\% dos respondentes afirmam desconhecer a existência destas. Entre os que afirmam ter conhecimento, pouco mais da metade soube informar o nome da associação. Este cenário influencia diretamente na participação, já que há um desconhecimento sobre as associações. Ademais, pode haver outros motivos, como a dificuldade em participar de uma associação, apontada por pelo menos 55\% dos respondentes.

Uma outra possibilidade para a baixa participação seria a ausência do que Abers (1998) chama de “janelas de oportunidade", o que levaria os cidadãos a terem sua participação condicionada à perspectiva de resultados concretos e, na ausência destes, a participação seria menor. Entretanto, 47,7\% dos respondentes não concordam que se sintam engajados somente quando há perspectivas de resultados concretos.

Por outro lado, há uma tendência maior dos cidadãos em se sentirem mais engajados a participarem dos acontecimentos do bairro quando estes participam da associação de moradores. Isto leva a crer que, quanto mais os cidadãos participam da associação, mais se sentem motivados a participar ativamente dos acontecimentos daquela localidade e da mesma forma o inverso. Porém, esse ciclo valeria também para a não participação. Neste último caso sendo necessárias ações que modifiquem o status quo.

\section{Dimensão 2: Percepção do Papel das Associações}

As associações de bairro são organizações com objetivos e finalidades específicos, ligados às necessidades e anseios locais. Nesse sentido, $73 \%$ dos respondentes acreditam que o papel de uma associação é buscar melhorias para o bairro, representando os desejos e necessidades da comunidade. Ainda, 44\% dos respondentes corroboram com esta assertiva ao afirmarem que a associação representa os anseios da comunidade em que vivem, que dá maior legitimidade e representatividade às cobranças e busca de melhorias para os bairros.

Além disso, 50\% dos respondentes acreditam que isso se deve à cobrança em relação aos órgãos públicos. Esta ideia coaduna com a proposta de Santos (2000) ao afirmar que as associações representam uma força capaz de provocar as autoridades na tomada de decisões em prol da comunidade. Visão esta que é semelhante à defendida pelo P2, que não vê a associação como uma forma de parceria com os órgãos públicos, mas sim como um canal exclusivo de cobrança destes, afinal, a associação possui maior força para tal do que se feita por atores isolados. Em contrapartida, os gestores do poder executivo local veem na associação um papel não só de cobrança, mas principalmente de coprodução do bem público e que, portanto, deve haver uma união entre os diversos atores para que haja efetividade das ações. 
Porém, não basta a associação representar os anseios da comunidade, buscar melhorias para o bairro ou cobrar as autoridades se não houver um canal de comunicação aberto com o poder local. Nesse sentido, quase $54 \%$ dos respondentes consideram que a associação seja um canal eficaz de comunicação com as instituições públicas. Em entrevista com os presidentes, todos corroboram com esta visão ao acreditarem no poder da coletividade em lugar das ações tomadas isoladamente, afinal, para eles, o governo municipal dá mais atenção às demandas feitas em nome de uma comunidade.

Em contrapartida, cerca de $50 \%$ dos respondentes não veem na associação um canal de acesso a acontecimentos políticos e econômicos da região, o que, como visto anteriormente, é um fator determinante para o engajamento da comunidade em debates políticos. Esta barreira prejudica o aperfeiçoamento da democracia nas localidades. Os presidentes e gestores entrevistados possuem visão semelhante, já que não percebem a associação como um canal de acesso a informações, o que leva a crer que o fluxo ocorre apenas de dentro do bairro para fora dele, como no caso das reivindicações da comunidade, porém, não parece haver um contrafluxo de informações e práticas.

Como visto, um dos papéis da associação é aproximar o cidadão do poder público, da política pública, e se tornar um canal de comunicação efetivo, dando acesso a esses acontecimentos. É possível perceber que as associações não têm cumprido plenamente seu papel no que tange à comunicação. Os dados mostram que não há um entendimento sobre como a associação pode fazer ponte entre o governo local e a comunidade, não apenas levando demandas, mas também trazendo respostas. O problema da comunicação é um fator determinante para a participação da população nas associações e engajamento nas questões do bairro. A falta de participação é ao mesmo tempo causa e consequência da falta de confiança nestas instituições.

\section{Dimensão 3: Política}

A dimensão política está presente em qualquer espaço democrático, visto que se pressupõe um espaço de diálogo, debate, reconhecimento de diferenças culturais, sociais e políticas, e de ideias que divergem, mas que contribuem para resolução de conflitos. Contudo, esta perspectiva pode ser observada, de maneira limitada, do ponto de vista partidário, eleitoral, onde a ideia de diálogo é substituída por interesses individuais. Sobre isto, dois dos presidentes entrevistados acreditam que a política, partidária e eleitoral, prejudica a associação de moradores, ressaltando que ambas estão passando por momentos difíceis e de baixa participação, que eles atribuem a conflitos políticos vivenciados na última eleição. O P3 (Presidente 3) aponta que na última eleição para presidência da associação, outros representantes da comunidade fizeram campanhas para candidatos opostos ao do atual presidente, porém, com o resultado da eleição, eles deixaram a associação de lado e se recusam a dar apoio às reuniões e projetos propostos. Já o $\mathrm{P} 1$ admite que mesmo a associação sendo um ente apartidário, o presidente por trás dela deve buscar dar apoio àquele candidato que demonstra vontade de ajudar a comunidade. Segundo o entrevistado, "A associação é apartidária, só que eu, como pessoa, tenho que pensar no que é melhor para minha comunidade. Naquela pessoa que eu acredito que tenha bons projetos para nossa comunidade".

Em entrevista com G2 (Gestor 2), este vê a associação apenas como um trampolim para políticos, como forma de se elegerem vereadores no município. Isto se dá, em parte, pela candidatura e eleição de um presidente de uma associação nas últimas eleições, bem como pela intenção de outros presidentes. Com relação a isto, quase $40 \%$ dos respondentes concordam com essa visão, enquanto outros $30 \%$ discordam, o que leva a crer que o papel de uma associação de moradores ainda é confuso, de maneira geral, para o cidadão, mas principalmente no que se refere ao envolvimento com questões políticas.

O P1 acredita que em relação ao processo eleitoral, todos os representantes eleitos deveriam passar por uma experiência em uma associação de moradores, para entenderem de forma mais completa a realidade vivida por cada bairro, levando, dessa forma, a processos mais democráticos. Ele menciona: "Hoje em dia, a associação de 
moradores, desde que vivida para o coletivo, é a maior representação, então, um candidato a vereador deveria passar pela experiência de um líder comunitário".

Com relação a outras questões envolvendo esse tema, houve uma maior discrepância apenas no que se refere ao papel da associação para escolha de um candidato durante uma eleição municipal, neste tópico, quase 60\% dos respondentes discordam que a associação de seu bairro ajude a escolher melhor os candidatos nas eleições.

Ao observar uma das reunióes de um presidente de uma das associações estudadas, com um dos gestores públicos, foi possível perceber que há um alinhamento entre estes no que diz respeito à busca de melhorias para a sociedade, o que reafirma a importância da associação como canal de comunicação, bem como demonstra certa abertura das instituições públicas à participação e debate, porém, este tipo de encontro ocorre de forma irregular e espaçada e, apesar de os gestores demonstrarem interesse em ouvir as demandas das comunidades, nem sempre o fazem em sua totalidade, ou não dão a atenção devida. Quando perguntado à comunidade a esse respeito, $45 \%$ acreditam que os órgãos públicos dão mais atenção aos bairros em que as associações são mais atuantes, justamente pela representatividade do presidente em relação à coletividade.

Como dito anteriormente, debates políticos pela busca de melhorias para a comunidade levam à formação de uma cultura política. Jacobi (1980) aponta que essa mobilização indica um avanço nos níveis de consciência da população em prol da democracia. No entanto, apesar de 37,5\% dos entrevistados acreditarem que a associação é responsável por trazer à tona esses debates, apenas uma parcela da população percebe o papel político da associação de moradores. Parte dos cidadãos ainda parece ter dúvidas quanto à promoção, por parte das associações, de debates políticos dentro das comunidades.

Nesse sentido, a associação, quando bem estruturada, é capaz de obter uma grande representatividade política, fortalecendo assim a sua representatividade frente aos órgãos públicos (Santos, 2002), porém, notase que o cidadão ainda não tem clareza quanto aos papéis de uma associação, principalmente no que se refere à representatividade política. Para Araujo, Tolentino e Theophilo (2009), se a participação é o principal acesso dos cidadãos aos acontecimentos políticos, tornando as pessoas responsáveis pela condução da comunidade, a "não participação" leva ao enfraquecimento desse espaço, podendo resultar em políticas assistencialistas que se configuram em "politicagem".

\section{Dimensão 4: Democracia}

O cenário de desconfiança em relação às instituições públicas brasileiras e em seus representantes está presente em todas as esferas. Em entrevista, P1 aponta que a questão da confiança é um ponto importante, pois "Quando o cidadão está desacreditado das instituições políticas, ele não vai cobrar de um vereador ou de um prefeito, mas sim daquele que está mais próximo dele, a associação de moradores”. Quase $50 \%$ dos respondentes acreditam que a associação tem um papel fundamental no fortalecimento da confiança dos cidadãos nas instituições públicas, ou seja, os cidadãos, desacreditados, tenderiam a procurar as organizações mais próximas deles, e estas ajudariam no desenvolvimento da confiança em outras instituições, o que acabaria por restabelecer a confiança geral. No entanto, a pouca participação pode ser um reflexo da crise política e econômica ainda recente, não tendo transcorrido o tempo necessário para que essas mudanças ocorram.

No que tange à dimensão sobre democracia, $57 \%$ dos respondentes acreditam que a associação de moradores ajuda no seu fortalecimento. O P1 ressalta que a democracia possibilita a troca de ideias e a participação, e que a associação de moradores tem justamente esse papel, de possibilitar debates. Contudo, o fortalecimento se dá através da construção de interesses comuns e, portanto, da participação, o que leva a crer que ainda há um caminho a ser percorrido nesse sentido.

Se a confiança social e política leva a uma maior participação, consequentemente tem-se um fortalecimento de valores democráticos e um possível crescimento econômico (Inkeles, 2001; Baquero 2008). Assim, é possível perceber a relação da associação de moradores no engajamento da população nos debates políticos e, como consequência, o fortalecimento da democracia. 
Esse envolvimento entre os cidadãos em tese levaria à união dos moradores de determinado bairro, o que também é percebido por $50 \%$ dos respondentes, que afirmam que, onde há associações de moradores atuantes as pessoas são mais unidas, reforçando, assim, o papel da associação no desenvolvimento de capital social.

A partir da análise de cada uma das dimensões, considerando como elemento o papel da associação, surgem as problemáticas apontadas, resumidas no Quadro 2, dando suporte também para o alcance das considerações feitas no tópico final.

Quadro 2 - Dimensões de análise

\begin{tabular}{|c|c|}
\hline Dimensão & Problemas Apontados \\
\hline Participação & $\begin{array}{l}\text { Falta de participação; Baixo } \\
\text { engajamento da população; } \\
\text { Alta rotatividade de } \\
\text { moradores; } \\
\text { Desconhecimento das } \\
\text { associações; Dificuldade } \\
\text { em participar de uma } \\
\text { associação; }\end{array}$ \\
\hline $\begin{array}{l}\text { Percepção } \\
\text { do Papel } \\
\text { das } \\
\text { Associações }\end{array}$ & $\begin{array}{l}\text { Falta de confiança } \\
\text { interpessoal; Baixa } \\
\text { participação nas } \\
\text { associaçôes; Dificuldade de } \\
\text { comunicação das } \\
\text { associaçôes com a } \\
\text { população; Associações não } \\
\text { são vistas como um canal } \\
\text { de acesso à discussão } \\
\text { relativa aos problemas } \\
\text { públicos; Reconhecimento } \\
\text { do papel exclusivamente de } \\
\text { cobrança; Pouca } \\
\text { articulação com instituições } \\
\text { públicas; }\end{array}$ \\
\hline Política & $\begin{array}{l}\text { Falta de compreensão do } \\
\text { papel da associação dos } \\
\text { moradores; Baixo } \\
\text { envolvimento da associação } \\
\text { no processo eleitoral } \\
\text { formal, quanto à educação } \\
\text { e conscientização da } \\
\text { população local; conflitos } \\
\text { políticos locais que } \\
\text { dificultam o papel de } \\
\text { representação da } \\
\text { associação de moradores; } \\
\text { Interesses políticos } \\
\text { envolvidos Associações } \\
\text { como "trampolim politico"; }\end{array}$ \\
\hline Democracia & $\begin{array}{l}\text { Baixo nivel de participação } \\
\text { e engajamento do cidadão; } \\
\text { Crise política e econômica } \\
\text { no cenário nacional; Pouco } \\
\text { incentivo a participação em } \\
\text { reuniốes e debates; }\end{array}$ \\
\hline
\end{tabular}

\section{Considerações Finais}

O Brasil tem como herança características fortemente clientelistas e paternalistas, o que historicamente acarretou uma participação política limitada e menos efetiva, bem como uma configuração ineficiente das 
instituições públicas, mantendo assim a reprodução dos velhos vícios. No imaginário da sociedade, constróise uma aversão ao serviço público ou, pelo menos, a ideia de dificuldade de acesso ao poder público.

$\mathrm{O}$ recente período de redemocratização trouxe à tona movimentos e organizações da sociedade civil no sentido de melhorar este cenário e ampliar a interação entre as esferas públicas e privadas. $O$ cidadão encontra meios de acessar direitos e buscar melhorias nos serviços públicos nas várias formas possíveis de representação. As associações comunitárias, ao lado de movimentos sociais e outras formas representativas, tornaram-se uma possibilidade de canal efetivo de comunicação entre o cidadão, a partir de sua realidade local, e o poder público.

Sendo assim, as associações de moradores mostram-se como importantes canais de construção do interesse público e do engajamento cidadão, principalmente no que se refere a questões como cultura política e democracia. A partir do contato com gestores de associações comunitárias, do poder público local e da própria comunidade, foi possível perceber que há o reconhecimento dos vários papéis das associações. No entanto, tendo como principal causa a falta de participação, percebe-se que estas organizações muitas vezes não conseguem alcançar seus objetivos ou não atuam da maneira como se espera.

A partir dos dados obtidos, conclui-se que o primeiro pressuposto, de que as associações comunitárias exercem importante papel no desenvolvimento da confiança das pessoas nas instituições públicas, se comprovou, mas ficou claro que isso só acontece com a participação e engajamento da população nas questões locais e em espaços como as associações. O segundo pressuposto, de que os gestores das associações comunitárias do município possuem pleno conhecimento do papel desempenhado por ela, comprova-se em parte, pois reconhecem o papel evidente das associações, mas, na prática, ainda falham na condução e na comunicação. $\mathrm{O}$ terceiro pressuposto, de que as instituições públicas locais estão abertas à participação e reconhecem o papel das associações foi comprovado na fala dos gestores ao afirmarem o papel de cobrança junto aos órgãos públicos. No entanto, ficou destacado que as associações não têm o papel apenas de cobrança e sim de atuação conjunta, em cooperação com os demais atores da sociedade, governo e população, o que ainda não se concretiza inteiramente. O quarto pressuposto é refutado, pois, apesar de a comunidade reconhecer o papel das associações, não há participação ativa. Este talvez seja o principal problema encontrado, em todas as dimensões de análise, já que a participação é condição essencial para desenvolvimento da confiança. $\mathrm{O}$ quinto pressuposto, de que os gestores percebem as associações como um meio de participação e de luta por melhorias na comunidade, bem como fundamentais para o desenvolvimento do capital social e da confiança nas instituições públicas, é confirmado na fala dos entrevistados, mas na prática a comunicação ainda é precária e questões políticas ainda interferem na sua atuação. Por fim, o sexto pressuposto, de que a confiança dos cidadãos nas instituições públicas aumenta quando as associações comunitárias desempenham seu papel efetivamente, é refutado justamente pela pouca participação da população nestes espaços. A atuação de forma colaborativa com outras instituições ainda não se dá de forma concreta e muitas vezes limita-se a cobranças sobre instituições públicas, considerando-se que a participação e confiança são conceitos indissociáveis e não há como afirmar que há confiança se não há participação.

O papel de uma associação comunitária é diverso: promover engajamento da população, debates políticos, formação de agenda, fortalecimento do capital social na comunidade, desenvolvimento da confiança entre os cidadãos e nas instituições públicas, representação popular, canal de comunicação com as instituições públicas, bem como cobrança dos órgãos públicos. Para que tenha efetividade, no entanto, ela precisa reafirmar o seu papel com os diferentes atores envolvidos na comunidade e interessados no desenvolvimento de sua região.

Percebeu-se que há um distanciamento concreto entre o que as associações de moradores percebem como seu papel e o que, efetivamente, fazem. Isto é reconhecido tanto por seus gestores quanto nos dados colhidos juntos à população. Pode-se atribuir parte do problema à dificuldade de comunicação e aproximação com o cidadão que, desconfiado, também não procura as associações como espaço que represente seus 
anseios. Verificou-se a falta de compreensão do real papel de uma associação de moradores na sua totalidade, principalmente no que se refere à dimensão política, tanto por parte dos gestores públicos no município quanto dos presidentes das associações e dos cidadãos em geral. É necessário um alinhamento das percepções entre os diferentes atores, de modo a estimular a participação e o engajamento, fortalecendo a dinâmica do capital social e, consequentemente, a efetividade das práticas democráticas.

As associações de moradores de São José exercem um papel importante na busca pela participação da população nos acontecimentos políticos e na tentativa de consolidação de um canal eficaz de comunicação com o poder público. Contudo, a baixa participação em reuniões e decisões coletivas impossibilita qualquer forma de debate, levando a ações menos eficazes. Sem o engajamento cidadão as associações passarão a ser uma entidade limitada, procurada apenas quando atendem à satisfação das necessidades pessoais e individuais, correndo o risco de se tornarem paternalistas e reprodutoras de programas governamentais.

A articulação em rede com outras organizações locais poderia ser, por exemplo, uma das soluções para sua limitada atuação política, entretanto, o clientelismo ainda visível nas práticas das associações pode ser um entrave no curto prazo. A atuação coletiva demandaria a construção de interesses comuns e a adoção de uma postura mais propositiva e questionadora frente ao poder público local.

Em síntese, foi possível perceber que as associações comunitárias não desempenham seu papel de forma efetiva no que diz respeito ao desenvolvimento da confiança da população. Apesar de ser reconhecida como espaço de representação, não há a promoção da educação política, do engajamento e participação do cidadão e tampouco do resgate da confiança das pessoas nas instituições públicas. É preciso que as associações redescubram o seu papel político, no sentido de que seus gestores passem a estimular a população a participar ativamente da vida política da comunidade e do processo democrático em seu município.

\section{REFERÊNCIAS}

Abers, R. (1998). Do clientelismo à cooperação: governos locais, políticas participativas e organização da sociedade civil em Porto Alegre. Cadernos IPPUR, 12(1), pp. 47-78.

Andion, C., Ronconi, L., Moraes, R. L., Gonsalves, A. K. R., Serafim, L. B. D. (2017). Sociedade civil e inovação social na esfera pública: uma perspectiva pragmatista. Revista de Administração Pública, 51(3), pp. 369-387.

Andion, C., Serva, M. (2004). Por uma visão positiva da sociedade civil: uma análise histórica da sociedade civil organizada no Brasil. Cayapa: Revista Venezolana de Economia Social, 4(7), pp. 7-24.

Ansell, C. K. (2012). Democratic Governance in a Pragmatist Key. Pragmatist Democracy: Evolutionary Learning as Public Philosophy. Oxford/New York, NY, Oxford University Press.

Araujo, C. A. L., Tolentino, M. A., Theophilo, C. R. (2009). Realidade Organizacional das associações comunitárias rurais da região sul de Montes Claros - MG. Anais do XXXIII Encontro da ANPAD, São Paulo. Recuperado em 12 de abril de 2017, de http://www.anpad.org.br/admin/pdf/CON2030.pdf.

Avritzer, L. (2012). Sociedade civil e Estado no Brasil: da autonomia à interdependência política. Opinião Pública, 18(2), pp. 383-398.

Baquero, M. (2001). Cultura política participativa e desconsolidação democrática: reflexões sobre o Brasil contemporâneo. São Paulo em Perspectiva, 15(4), pp. 98-104.

Baquero, M. (2003). Construindo uma outra sociedade: o capital social na estruturação de uma cultura política participativa no Brasil. Revista de Sociologia e Política, (21), pp. 83-108.

Baquero, M. (2008). Democracia formal, cultura política informal e capital social no Brasil. Opinião Pública, 14(2), pp. 380-413.

Bobbio, N. (2007). Estado, governo, sociedade: para uma teoria geral da politica (14ª Ed.). Rio de Janeiro: Paz e Terra.

Cohen, J. L. (2007). Civil Society and Globalization: Rethinking the Categories. In L. Trägårdh (Ed.), State and Civil Society in Northern Europe: The Swedish Model Reconsidered (pp. 37-66). New York; Oxford: Berghahn Books.

Cohen, J. L., Arato, A. (1994). Civil society and political theory. MIT press. 
Julia De Marchi, et al. O papel das Associações Comunitárias na Promoção da confianÇa do cidadão e...

Dagnino, E. (1998). Sociedade civil e democracia: reflexões sobre a realidade brasileira. Revista Idéias, 5(2)/.(1), pp. $13-42$.

Fukuyama, F. (1995). Trust: The social virtues and the creation of prosperity. New York: The Free Press.

Fung, A. (2003). Associations and democracy: Between theories, hopes, and realities. Annual review of sociology, 29(1), pp. 515-539.

Gomes, M. F. C. M. (2015). Política social e cultura política. Revista de Políticas Públicas, 6(1), pp. 113-125.

Habermas J. (1996). Between Facts and Norms: Contributions to a Discourse Theory of Law and Democracy. Transl. W Rehg. Cambridge, MA: MIT Press

Heideman, L. J. (2018). Making civil society sustainable: The legacy of USAID in croatia. VOLUNTAS: International Journal of Voluntary and Nonprofit Organizations, 29(2), pp. 333-347.

Ibope. (2019). Índice de Confiança Social 2019. São Paulo: Ibope Inteligência.

Inkeles A. (2001). Measuring social capital and its consequences. In J.D. Montgomery A. Inkeles (Ed.), Social Capital as a Policy Resource. Boston, MA: Springer.

Jacobi, P. R. (1980). Movimentos sociais urbanos no Brasil. Revista Brasileira de Informação Bibliográfica em Ciências Sociais, 9(1), pp. 221-236.

Kuschnir, K., Carneiro, L.P. (1999). As dimensões subjetivas da política: cultura política e antropologia da política. Revista Estudos Históricos, 13(24), 227-250.

Laniado, R. N. (2001). Troca e reciprocidade no campo da cultura política. Sociedade Estado, 16(1-2), pp. 222-244.

Latinobarómetro. (2018). Informe 2018. Buenos Aires: Latinobarómetro. Recuperado de https://www.latinobarome tro.org/latdocs/INFORME_2018_LATINOBAROMETRO.pdf

Lavalle, A. G., Szwako, J. (2015). Sociedade civil, Estado e autonomia: argumentos, contra-argumentos e avanços no debate. Opinião Pública, 21(1), pp. 157-187.

Lüchmann, L. H. H. (2016). Associativismo e democracia: um estudo em Florianópolis. Florianópolis: Editora UFSC.

O'Donnell, G. (1987). Transição democrática e políticas sociais. Revista de Administração Pública, 21(4), pp. 9-16.

Putnam, R. D. (2005). Comunidade e democracia: a experiência da Itália Moderna (4a ed.). Rio de Janeiro: FGV.

Santos, A. S. R. (2000). A importância das associações de bairro. Última arca de Noé. Recuperado de http:// www.ultimaarcadenoe.com.br/urbanismoassociacoes.htm\&gt;.

Santos, P. L (2002). A comunidade em ação no combate à criminalidade. Relatório Final de Pesquisa apresentado à Fapesp. Processo n ${ }^{\circ}$ 01/00070-1. Marilia.

Teixeira, M. L. M., Popadiuk, S. (2003). Confiança e desenvolvimento de capital intelectual: o que os empregados esperam de seus líderes?. Revista Administração Contemporânea, 7(2), pp. 73-92.

Transparência Internacional. (2019). Indice de Percep̧̧ão da Corrup̧̧ão 2019. Berlin: Transparência Internacional. Recuperado de https://comunidade.transparenciainternacional.org.br/asset/67:indice-de-percepcao-da-corrup cao-2019? stream $=1$ 